Research Article

\title{
Acoustic Velocity Correcting Method for the Tilted Acoustic Tube in Testing of Pile by Ultrasonic Transmission
}

\author{
Yongqiang Cui $\mathbb{D}^{1}{ }^{1}$ Zhitao Ma $\mathbb{D}^{1,2}$ Yachao Yang ${ }^{1}{ }^{1},{ }^{1}$ and Daifu Song ${ }^{1}{ }^{1}$ \\ ${ }^{1}$ College of Energy and Mining Engineering, Shandong University of Science and Technology, Qingdao, Shandong 266590, China \\ ${ }^{2}$ State Key Laboratory of Mining Disaster Prevention and Control Co-founded By Shandong Province \\ and the Ministry of Science and Technology, Shandong University of Science and Technology, Qingdao 266590, China
}

Correspondence should be addressed to Zhitao Ma; mztsdkj@163.com

Received 28 July 2020; Revised 4 November 2020; Accepted 7 November 2020; Published 21 November 2020

Academic Editor: Guojun Wu

Copyright (c) 2020 Yongqiang Cui et al. This is an open access article distributed under the Creative Commons Attribution License, which permits unrestricted use, distribution, and reproduction in any medium, provided the original work is properly cited.

\begin{abstract}
The finite element software ABAQUS was used to simulate the detection of piles by ultrasonic transmission. The influence of the tilted acoustic tube on the testing results of the pile was analyzed. The results showed that, when the pile was complete, the velocity of the sound-depth curve of the received signal was inclined to one side due to the inclination of the acoustic tube and the velocity of the sound seriously deviated from the normal value; when there was a defect in the pile, the signal of the defect was not obvious due to the tilt of the acoustic tube, which was easy to miss or misjudge the defects of the pile. To solve the problem of the inclined acoustic tube, the mathematical model of the position relation of the acoustic tube was established, and the method for correcting the velocity of the sound based on the angle of the acoustic tube was derived. Numerical simulation and engineering examples were used to verify the modified method; the verification showed that the corrected acoustic signal could accurately determine the defects and their positions in the pile, and this method effectively reduced the influence of the tilted acoustic tube on the detection signal, which was beneficial to improve the accuracy of the testing for the pile.
\end{abstract}

\section{Introduction}

Ultrasonic transmission is widely used to test the integrity of the pile because the accuracy of this test is very good, and it is not limited by the length and diameter of the pile and it is easy to collect and analyze the detected signals [1]. However, the specification [2] of the ultrasonic transmission clearly requires that the acoustic tube be parallel. In fact, it is often difficult to achieve this in the construction of the pile. Especially in the bored pile without the reinforcing cage, the acoustic tube often tilts, which affects the accuracy of the testing and causes the misjudgment of the defect in the pile. It brings hidden dangers to the quality of the project [3]. The problem of the inclination of the pre-buried acoustic tube has been plaguing the testers of the pile. In view of this problem, many domestic scholars have carried out relevant researches. In [4], the abnormal characteristics of the detected data are analyzed when the acoustic tube is tilted and a method in which abnormal features are eliminated by reasoning is proposed. In [5], a comprehensive method to evaluate the detected data of acoustic transmission is proposed, which effectively improves the objectivity and scientific nature of the analysis and processing of the detected data. In [6], the function of wavelet which is constructed by one-dimensional wavelet is used to correct the acoustic tube. In [7], the principle of polynomial fitting to eliminate the influence of the inclined acoustic tube is used. In [8], the least squares method of the series of powers is used to fit the time of the sound to depth curve and then the acoustic tube is corrected. The above researches essentially use the fitting elimination. This method requires a lot of segmentation and fitting, which has a large workload and a large personal error. Based on the ABAQUS numerical simulation software, this paper analyzes the influence of the inclined acoustic tube on the results of testing of the pile and proposes a method for correcting the velocity of sound based on the angle of the acoustic tube and verifies the corrected results through numerical simulation. The results show that the corrected 
velocity of the sound has a good consistency with the velocity of the sound when the acoustic tube is parallel, and we can accurately determine the position of the defect in the pile.

\section{Numerical Simulation}

2.1. Numerical Model. The influence of the inclination of the acoustic tube on the detected signal was studied by ABAQUS numerical simulation software. Since the process of the simulation focuses on the changes of the detected signals in the testing of the pile, the pile and soil model adopted the criterion of the linear elasticity [9]. The physical and mechanical parameters of the pile and soil are shown in Table 1.

Figure 1 shows the complete pile with the acoustic tube. The pile was a square pile; its length was $1 \mathrm{~m}$, width was $1 \mathrm{~m}$, and height was $8 \mathrm{~m}$. Two acoustic tubes were arranged in the pile. The diameter of the acoustic tube was $5 \mathrm{~cm}$, and the length was $8 \mathrm{~m}$. The acoustic tube was $5 \mathrm{~cm}$ from the edge of the pile. Figure 1(a) shows the model of the complete pile when the acoustic tubes were parallel. Figure 1(b) shows the model of the complete pile when the right acoustic tube was inward tilted by 3.2 degrees. The contact between the pile and the soil was set as follows: surface to surface contact was adopted between the side of the pile and the soil around the pile, the tangential behavior was rough, and the normal behavior was hard contact; tie constraints were adopted between the bottom of the pile and the soil at the bottom of the pile [10]. The influence of the artificial boundary on the detected signal was considered; this model used the infinite element to simulate the infinite boundary to eliminate the reflection of the artificial boundary [11]. Both the pile and the soil used the C3D8R element, which was three-dimensional and eight-node. The mesh of the model is shown in Figure 2. It used the mode of sweep from top to bottom. The mesh of the soil near the pile was dense, and the mesh of the soil away from the pile was sparse. From the top of the pile, loading nodes were established every $20 \mathrm{~cm}$ in an acoustic tube, and the nodes in another acoustic tube were correspondingly set as receiving nodes. Moreover, the loading node was guaranteed to be on the same horizontal plane with the corresponding receiving node.

2.2. Duration of the Step. The ultrasonic testing of the piles was performed by $2 P$ waves. According to the formula for solving the velocity of the longitudinal waves [12], the velocity of the three-dimensional Pwave in the testing of the pile can be calculated as follows:

$$
\begin{aligned}
C_{P} & =\sqrt{\frac{1-\mu}{(1+\mu)(1-2 \mu)} \frac{E}{\rho}}=\sqrt{\frac{3.0 \times 10^{10} \times 0.83}{2500 \times 1.17 \times 0.66}} \\
& =3591.41 \mathrm{~m} / \mathrm{s} .
\end{aligned}
$$

The horizontal testing of the piles with the parallel acoustic tube was carried out, and the time of the propagation of the elastic wave in the pile was obtained as follows:

$$
t=\frac{l^{\prime}}{C_{P}}=\frac{0.8}{3591.41}=0.00022 \mathrm{~s},
$$

where $l^{\prime}$ is the clear distance between the inner walls of the two acoustic tubes in each profile for testing. In order to ensure that the elastic wave can propagate from the loading point to the signal receiving point, the time of the calculation was slightly greater than the time the elastic wave propagated in the pile. In the calculation of the model, the total time of the step was $0.0003 \mathrm{~s}$, and the increment of the time was $10^{-6} \mathrm{~s}$.

2.3. Condition of Load. The most basic form of vibration of particle in the elastic solid was simple harmonic vibration. In the actual detection, the wave of the sound emitted by the ultrasonic transmitter had simple harmonic characteristics, so a simple harmonic force was adopted to simulate the wave of the sound [13]. In order to be closer to the harmonic signal emitted by the ultrasonic transmitter, the convex cosine function [14] was used as the simple harmonic force, as shown in the following equations:

$$
\begin{aligned}
P(t) & =P_{0} f(t ; n), \\
f(t ; n) & = \begin{cases}\frac{(-1)^{n}}{2}\left[1-\cos \left(\frac{\omega_{0}}{n} t\right)\right] \cos \left(\omega_{0} t\right), & 0 \leq t \leq n \frac{2 \pi}{\omega_{0}}, \\
0, & t>n \frac{2 \pi}{\omega_{0}},\end{cases}
\end{aligned}
$$

where $\omega_{0}=2 \pi f_{0}, f_{0}$ is the center frequency, and $n$ is a positive integer 2 , which controls the sharpness of the signal. The pattern of the load is shown in Figure 3. The horizontal load $P_{0}$ was $10 \mathrm{~N}$. The loading time for a complete cycle was $10 \mu \mathrm{s}$.

\subsection{Numerical Results and Analyses}

2.4.1. Results of the Complete Pile. There were 41 detections of numerical simulation, respectively, carried out for the model of the complete pile with the parallel acoustic tube and the inclined acoustic tube, and the horizontal velocity of each receiving point was extracted, respectively. Figure 4 shows the velocity-time curve of the receiving point at a depth of $4 \mathrm{~m}$ when the acoustic tube was parallel. The time of the first positive peak of the velocity to time curve on each receiving point was extracted separately. According to formula (5), the vocal velocity of each receiving point was calculated, and then, the vocal velocity-depth curve was drawn:

$$
v=\frac{l_{0}}{t_{\mathrm{p}}-t^{\prime}},
$$

where $v$ is the velocity of the sound, $l_{0}$ is the distance between the two acoustic tubes at the top of the pile, $t_{\mathrm{p}}$ is the time of the first positive peak in the velocity-time curve of each 
TABLE 1: Physical and mechanical parameter of the pile and soil.

\begin{tabular}{lcccccc}
\hline & Length $(\mathrm{m})$ & Diameter $(\mathrm{m})$ & Concrete grade & Elasticity modulus $(\mathrm{pa})$ & Density $\left(\mathrm{kg} / \mathrm{m}^{3}\right)$ & Poison's ration \\
\hline Pile & 8 & 1.0 & C30 & $3 \times 10^{10}$ & 2500 & 0.17 \\
Soil & 16 & 10 & - & $1 \times 10^{8}$ & 1900 & 0.4 \\
\hline
\end{tabular}

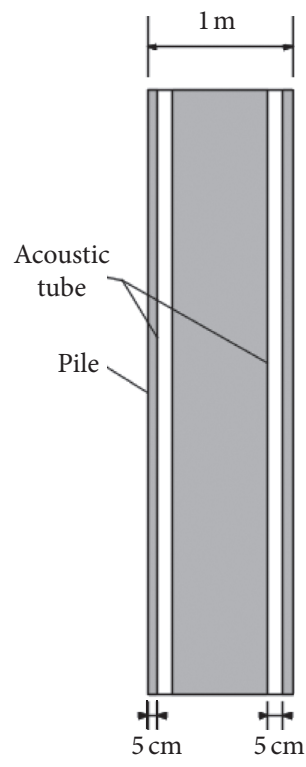

(a)

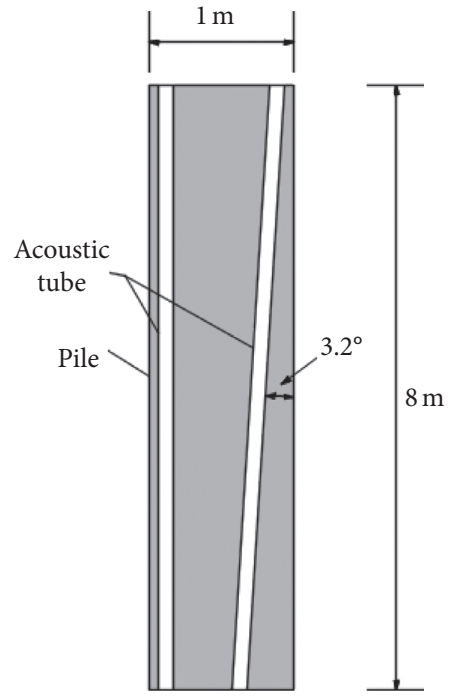

(b)

FIgUre 1: The model of the pile with the acoustic tube. (a) Parallel acoustic tube and (b) tilted acoustic tube.

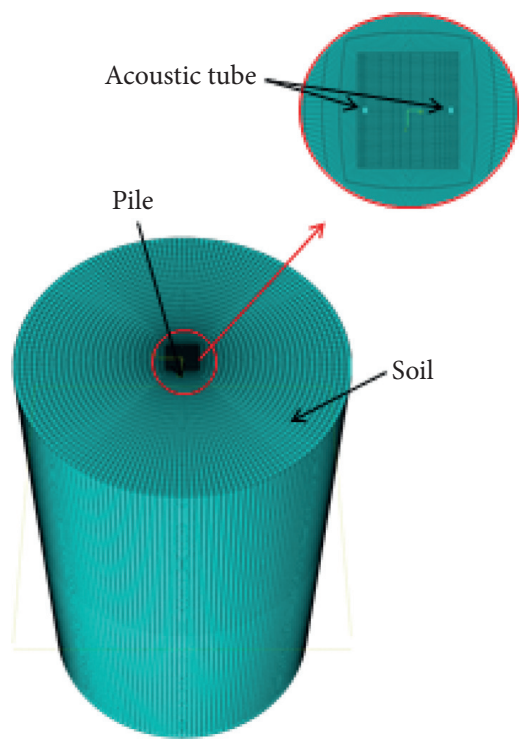

FIGURE 2: The meshing of the model.

receiving point, and $t^{\prime}$ is the time of the first positive peak in the curve of the load.

Figure 5 shows the results of ultrasonic inspection of the complete pile when the acoustic tube was parallel and the acoustic tube was tilted. It could be seen that the velocity of the sound when the acoustic tubes were parallel was unchanged from the top of the pile to the bottom of the pile, and when the acoustic tube was tilted inward, the speed of the sound gradually increased within the depth of the pile.

2.4.2. Results of the Pile with Cavity. Figure 6 shows a model of the pile with cavity. The length of the cavity was $0.1 \mathrm{~m}$, the width was $0.1 \mathrm{~m}$, and the height was $0.4 \mathrm{~m}$, which was located in the middle of the pile. The top surface of the cavity was 


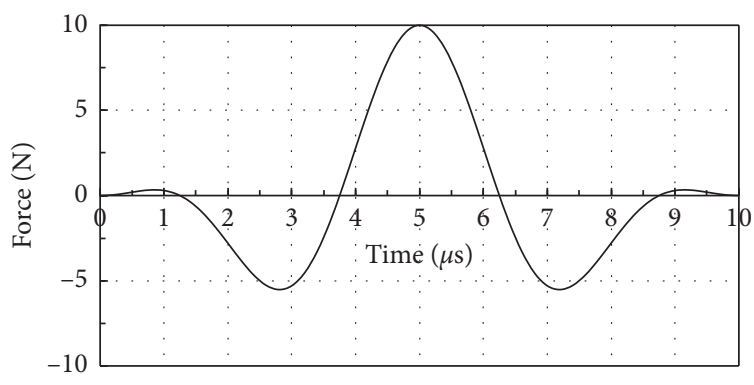

Figure 3: The load-time curve.

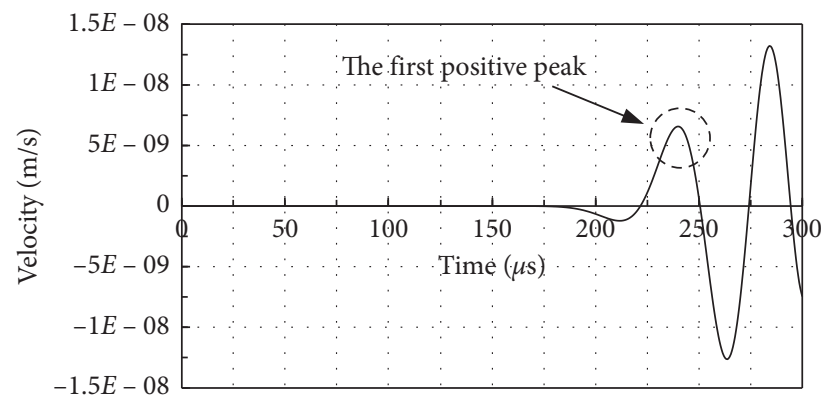

FIGURE 4: The velocity-time curve of receiving point at a depth of $4 \mathrm{~m}$.

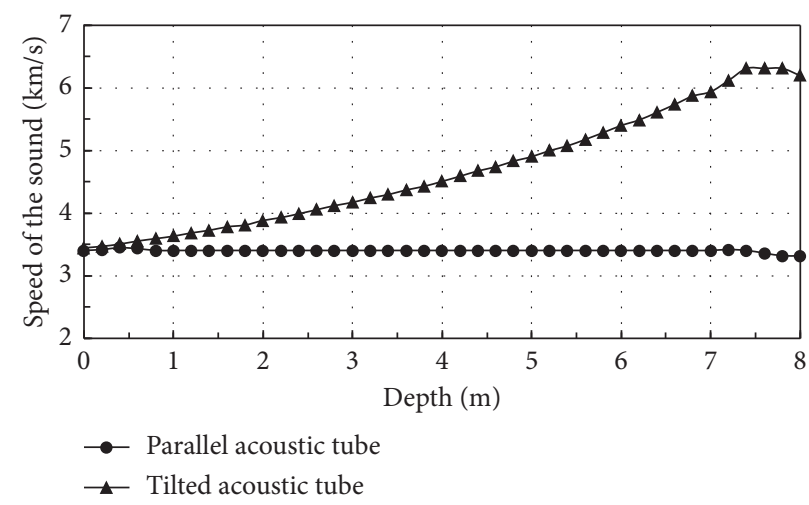

FIGURE 5: The results of the complete pile with the tilted acoustic tube and the parallel acoustic tube.

$3.8 \mathrm{~m}$ from the top of the pile. The physical and mechanical parameters of the defective pile and the arrangement of the internal acoustic tube were consistent with those of the previous complete pile.

Figure 7 shows the results of ultrasonic inspection of the pile with the cavity when the acoustic tube was parallel and the acoustic tube was tilted. Figure 7(a) shows the vocal velocitydepth curve of the detection of the defective pile when the acoustic tubes were parallel. It could be found that the vocal velocity remained unchanged in the nondefective section of the pile, while it began to decrease sharply near the defect from $3.8 \mathrm{~m}$ to $4.2 \mathrm{~m}$ in depth, and it reached a minimum of $3333 \mathrm{~m} / \mathrm{s}$. The signal of the defect was very obvious. Figure $7(\mathrm{~b})$ shows the testing results of the defective pile when the acoustic tube was tilted. It could be seen that, due to the inclination of the acoustic tube, the speed of the sound gradually increased within the length of the pile. The speed of the sound was only slightly reduced at the position of the cavity. The signal of the defect was not obvious, and it was easy to cause the defect to be missed. Therefore, it was necessary to correct the vocal velocity-depth curve when the acoustic tube was tilted. This paper proposed a method based on the angle of the acoustic tube to correct the velocity of the sound.

\section{Correcting Method}

3.1. Principle of Correction. The inclined section of the acoustic tube was divided by the turning point of the vocal velocity-depth curve as the cutoff point. As shown in Figure 8 , the distance between the two acoustic tubes at the top of the pile was set to be $l_{0}$, the measured time of the sound was $t_{0}$, and the speed of the sound was $v_{0}$. The acoustic tube 


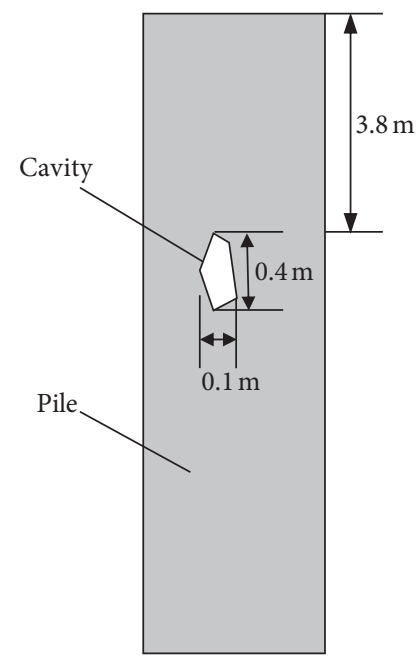

Figure 6: The model of pile with cavity.

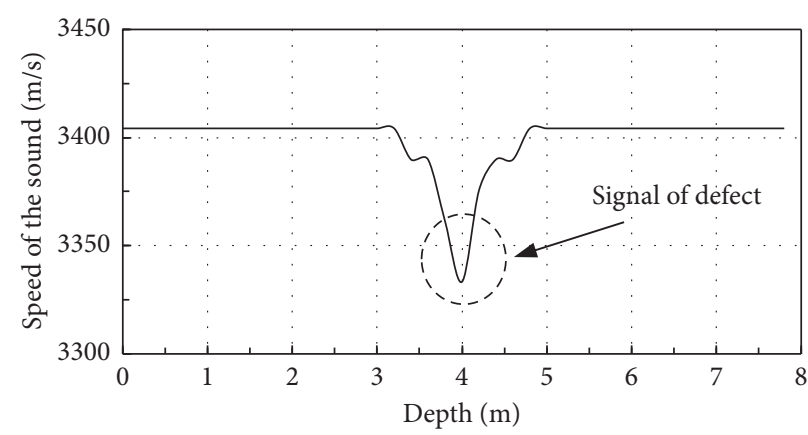

(a)

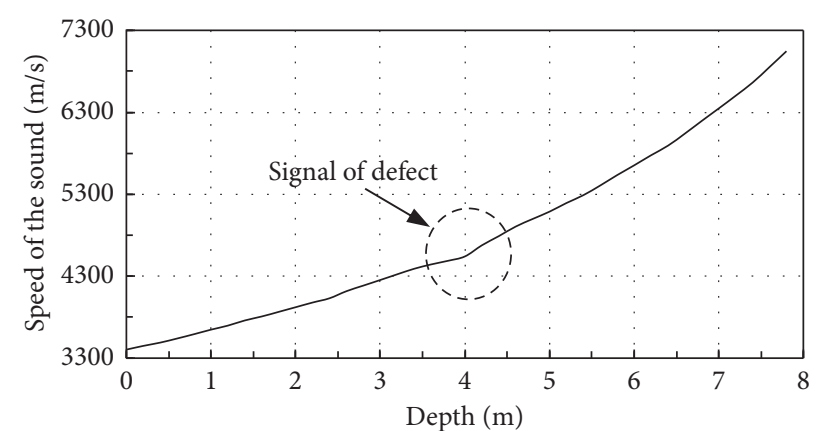

(b)

Figure 7: The results of defective piles with parallel acoustic tube and inclined acoustic tube. The results of the defective pile with (a) the parallel acoustic tube and (b) the inclined acoustic tube.

$A$ was vertical, and the $\mathrm{BC}$ section of the acoustic tube $B$ was inclined. Points $A$ and $B$ were horizontal testing. The distance between the acoustic tubes $A$ and $B$ was set to be $l_{1}$, the measured sound time was $t_{1}$, and the speed of the sound was $v_{1}$. Keep point $A$ still and move point $B$ down to $\Delta H$ to point $C$. Points $A$ and $C$ were oblique testing. The distance between $A$ and $C$ was $l_{2}$, the measured time of the sound was $t_{2}$, and the velocity of the sound was $v_{2}$. The vertical distance between the two points $B$ and $C$ was $\Delta H$. According to the geometric relationship, the following equations were established:

$$
\begin{aligned}
& \sin \gamma=\frac{\Delta H}{l_{2}} \approx \frac{\Delta H}{t_{2} v_{0}}, \\
& \tan \alpha=\frac{t_{1} v_{1}-(\Delta H / \tan \gamma)}{\Delta H} .
\end{aligned}
$$

Combine formulas (6) and (7) to obtain the inclination angle of the acoustic tube:

$$
\tan \alpha \approx \frac{1}{\sin \gamma} \frac{t_{1}}{t_{2}}-\frac{1}{\tan \gamma}
$$

For other receiving points of the inclined section, the real distance of the acoustic tube can be obtained as follows:

$$
l_{i}=l_{0}-H_{i} \tan \alpha .
$$

According to the measured sound time of each measuring point, the true velocity of the sound can be obtained as follows:

$$
v_{i}=\frac{l_{i}}{t_{i}}=\frac{l_{0}-H_{i} \tan \alpha}{t_{i}},
$$

where $l_{i}$ is the corrected distance between the two acoustic tubes at the measuring point $i, H_{i}$ is the vertical distance between the measuring point $i$ and the turning point, $t_{i}$ is the measured time of the sound at the measuring point $i, 1_{0}$ is the distance between the two acoustic tubes at the top of the pile, and $v_{i}$ is the corrected speed of the sound at the measuring point $i$. 


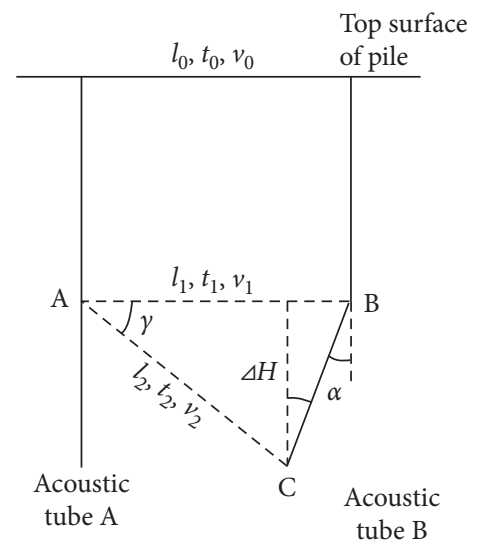

FIgURE 8: The schematic diagram of the pile with the inclined acoustic tube.

3.2. Validation of Corrected Result. The velocity of the sound in the case where the acoustic tube was tilted was corrected by the above method. According to the velocity of the sounddepth curve in Figure 7(b), it could be found that the velocity of the sound gradually increased with the increase of depth, and the velocity of the sound at the last point reached $7045 \mathrm{~m} / \mathrm{s}$, indicating that there was an obvious inclination of the acoustic tube. The above method of correction was applied to determine the inclined angle of the acoustic tube at the depth of $3 \mathrm{~m}, 6 \mathrm{~m}$, and $7 \mathrm{~m}$, respectively, and took the average value of $\alpha=3.21^{\circ}$. The tangent of $\alpha$ was equal to 0.0561 . The speed of the sound was corrected according to equation (10). The corrected speed of the sound-depth curve is shown in Figure 9. It could be seen that the corrected velocity of the sound-depth curve had a slight fluctuation within the range of the no-defective section in the pile, which was approximately unchanged. The velocity of the sound decreased sharply at the position of the defect at the depth of $3.8 \mathrm{~m}-4.2 \mathrm{~m}$. The signal of the defect fluctuated significantly. The corrected velocity of the sound-depth curve was very similar to the detected result when the acoustic tube was parallel. The results showed that the defect of the pile and its position can be accurately judged based on the velocity of the sound-depth curve after being corrected by the inclined angle of the acoustic tube. It can solve the problem of misjudgments and missing judgment of defects caused by the inclination of the acoustic tube.

\section{Practical Engineering}

4.1. Engineering Profile. No.13 pile was detected at No. 45 pier of a construction site, the strength of the concrete was $\mathrm{C} 20$, the diameter of the pile was $1 \mathrm{~m}$, the effective length of the pile was $5.25 \mathrm{~m}$, and the two acoustic tubes (Figure 10) were symmetrically distributed. The RS-ST01 C ultrasonic detector (Figure 11) produced by Wuhan Haiyan Company was used, the transducer was ZDBS-YGD type, which was interchangeable with the transmitter and receiver, and its frequency was $45 \mathrm{KHz}$. The horizontal testing was adopted, and the distance between measuring points was $25 \mathrm{~cm}$. The

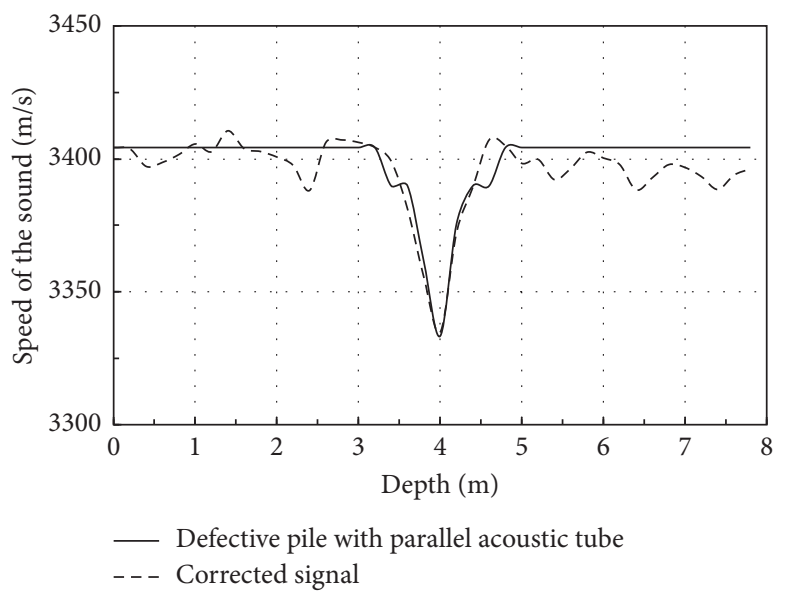

Figure 9: The corrected signal.

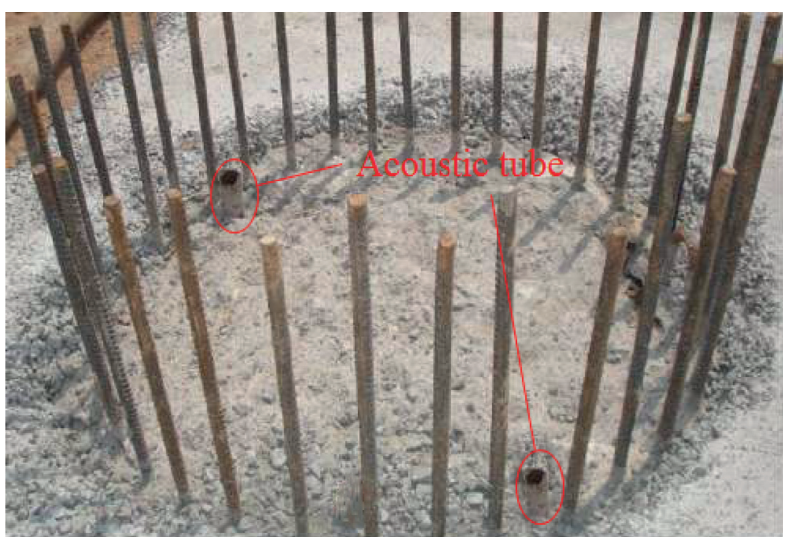

FIgURe 10: Layout of the acoustic tube.

test was conducted point by point from the top to the bottom of the pile.

4.2. Analysis of Correction. After analysis, the sound velocity at the top of the pile was $4468 \mathrm{~m} / \mathrm{s}$ and the sound velocity at the bottom of the pile was $4386 \mathrm{~m} / \mathrm{s}$. The overall trend of the 


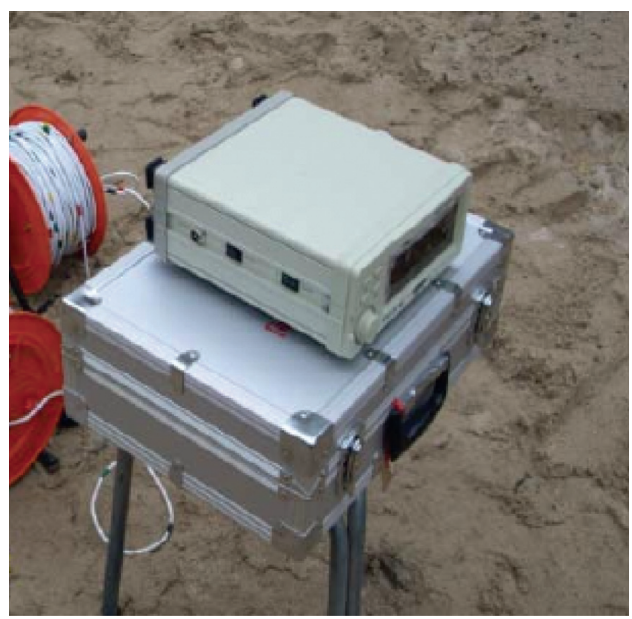

FIGURE 11: RS-ST01 C ultrasonic detectors.

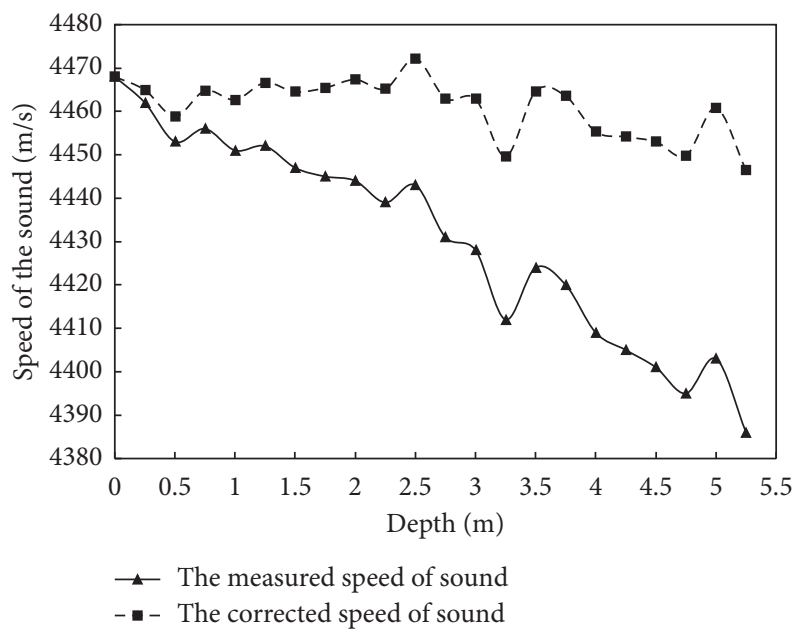

Figure 12: Corrected speed of the sound-depth curve.

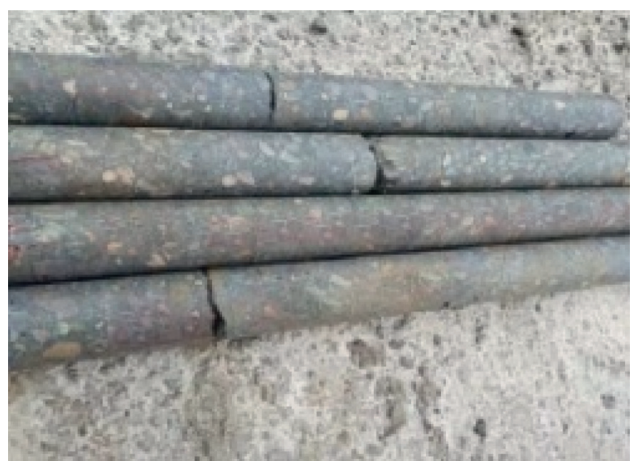

Figure 13: Core sample.

speed of the sound-depth curve was gradually decreasing, which indicated that the acoustic tube was inclined, so the integrity of the pile cannot be determined. The method proposed in this paper was used to determine the inclination angle of the acoustic tube at $1 \mathrm{~m}, 3 \mathrm{~m}$, and $4 \mathrm{~m}$, respectively, and calculated the average value. The tangent of $\alpha$ was equal to 0.0021 . The speed of the sound was corrected according to equation (10). The corrected speed of the sound-depth curve is shown in Figure 12. It can be seen that the corrected speed of the sound-depth curve tended to be horizontal and had a slight fluctuation from the top of the pile to the bottom of the pile. It showed that the pile was relatively complete.

In order to verify the accuracy of this correction method, the integrity of the pile was verified by the core drilling method at the scene. The diameter of the concrete core sample was $86 \mathrm{~mm}$. As shown in Figure 13, the concrete core of the pile was continuous, complete, and long columnar, with smooth surface, good cementation, uniform distribution of aggregates, and basically consistent fractures, with only a few pores on the side of the core. Through comprehensive determination of the drilled core samples, it can be seen that pile was relatively complete. The results were consistent with the corrected speed of the sound-depth curve, which showed that the method for correcting the velocity of the sound based on the angle of the acoustic tube can reduce the influence of the inclined acoustic tube on the detection results.

\section{Conclusions}

The detection of the pile by the ultrasonic transmission is greatly affected by the inclination of the acoustic tube [15]. According to the analysis of simulation and experimental results, the following conclusions can be drawn:

(1) When the acoustic tube tilts, the velocity of the sound-depth curve of the received signal will tilt to one side, which will cause the wrong judgment of internal defects in the pile.

(2) The method for correcting the velocity of the sound based on the angle of the acoustic tube was proposed in this paper. Through numerical simulation verification, it is found that this method effectively reduces the influence of the tilted acoustic tube on the detection signal. It is helpful to improve the accuracy of the inspectors' judgment on the integrity of piles.

(3) Combined with the pile in engineering, it is found that the modified ultrasonic testing results are in good agreement with the core drilling method, which further indicates that the modified method has a high accuracy.

\section{Data Availability}

The processed data required to reproduce these findings cannot be shared at this time as the data also form a part of an ongoing study.

\section{Conflicts of Interest}

The authors declare that they have no conflicts of interest.

\section{Acknowledgments}

The research was supported by the First-Rate Discipline Construction Program of Mining Engineering (01LX03303). 


\section{References}

[1] H. Seo, "Monitoring of CFA pile test using three dimensional laser scanning and distributed fiber optic sensors," Optics and Lasers in Engineering, p. 130, Article ID 106089, 2020.

[2] S. Yang, J. Liu, A. Garg, and M. Zhang, "Analytical solution for estimating bearing capacity of a closed soil plug: verification using an on-site static pile test," Journal of Marine Science and Engineering, vol. 8, no. 7, 2020.

[3] N. Xu and S. Huo, "A new measurement system of large-scale steel pipe pile test for offshore wind farm," Journal of Coastal Research, vol. 103, no. sp1, 2020.

[4] W. Zhou, "Influence of the non-parallel detection tube on the detection data of ultrasonic transmission method and its correction method," Journal of Hunan University, no. 11, pp. 136-140, 2008, in Chinese.

[5] Li Ting, Z. Xu, and J. Luo, "Study on the evaluation system of test data for pile acoustic wave transmission method," Rock and Soil Mechanics, vol. 31, no. 10, pp. 3165-3172, 2010, in Chinese.

[6] X. Zhang and Y. Lv, "Analysis of the acoustic wave of the acoustic tube during the pile foundation detection by acoustic wave transmission method," Journal of Vibration, Measurement and Diagnosis, vol. 32, no. 04, pp. 649-654, 2012, in Chinese.

[7] C. Zhao and D. Yang, "Study on the method of correcting the spacing of acoustic tube in the pile test," Journal of Railway Engineering Society, vol. 31, no. 11, pp. 25-29, 2014, in Chinese.

[8] Y. Jin and S. Tong, "Study on correction of acoustic tube length in acoustic wave transmission detection of cast-inplace pile," Journal of Building Materials, no. 4, pp. 349-352, 1999, in Chinese.

[9] R. H. Howard and A. E. Ruggles, "Design and out-of-pile testing of a novel irradiation experiment vehicle to support qualification of nuclear thermal propulsion components," Nuclear Engineering and Design, vol. 361, Article ID 110516, 2020.

[10] W. Wu, X. Xu, H. Liu et al., "Vertical vibration characteristics of a variable impedance pile embedded in layered soil," Mathematical Problems in Engineering, vol. 2017, Article ID 1794950, 11 pages, 2017.

[11] C. Dong and Z. Hu, "Study on correction method of acoustic tube diameter by acoustic transmission method," Science and Technology Innovation and Application, no. 15, pp. 3-4, 2016, in Chinese.

[12] J. . Carette and S. Staquet, "Monitoring the setting process of eco-binders by ultrasonic P-wave and S-wave transmission velocity measurement: mortar vs concrete," Construction and Building Materials, vol. 110, pp. 32-41, 2016.

[13] S. Wei, Y. Zhang, and M. R. Jones, "Using the ultrasonic wave transmission method to study the setting behavior of foamed concrete," Construction and Building Materials, vol. 51, pp. 62-74, 2014.

[14] Y. Zhang, K. H. Andersen, and P. Jeanjean, "Verification of a framework for cyclic p-y curves in clay by hindcast of Sabine River, SOLCYP and centrifuge laterally loaded pile tests," Applied Ocean Research, vol. 97, Article ID 102085, 2020.

[15] M. Aghayarzadeh, H. Khabbaz, B. Fatahi, and S. Terzaghi, "Interpretation of dynamic pile load testing for open-ended tubular piles using finite-element method," International Journal of Geomechanics, vol. 20, no. 2, 2020. 